\title{
The Indian Newspapers and American Presidential Election 2016: A Content Analysis of Photo Coverage
}

\author{
MadhuBabuJangili ${ }^{1}$, NageswaraRaoNamburu ${ }^{2}$ \\ ${ }^{1}$ Assistant Professor, Department of Journalism and Mass Communication, AcharyaNagarjuna \\ University, Guntur, Andhra Pradesh, India \\ ${ }^{2}$ Research Scholar, Department of Journalism and Mass Communication, AcharyaNagarjuna \\ University, Guntur, Andhra Pradesh, India
}

\begin{abstract}
The study is a quantitative content analysis of the photo coverage of American president election 2016 by Indian Newspapers. The principal goal of the study was to find out the selected newspapers interest to cover the election. The study also sought to determine the more favorable and less favorable. Which newspapers covered the election photo coverage? A purposive continues sample was used to selected newspapers with in the study period i.e. September 7, 2016 to November 5, 2016 for analysis there were 124 photos identified. The study utilized the framing theory as basis for the analysis of the photos.
\end{abstract}

Keywords: U.S. Presidential Election, Hillary Clinton, Donald Trump, Photo Coverage.

\section{INTRODUCTION}

Media has been criticized for enabling Donald Trump's candidacy by not taking him on in the early stages of the Republic of nomination process. Initially, the employed the media while Trump was expressing ‘politically unconventional opinions`, like banning Muslims and buildings walls to keep out Mexicans, his view was one among many, this tendency, none as false equal lance, lent equal authenticity to fat and to opinions and categorized bigotry as a form of free speech. Media has adopted a similar approach to other polarized debates, like limitations of the free market and marriage. Equality for sexual minorities because those facts offend the beliefs of millions of Americans. However the news media obsession with not offending audiences is not a manifestation of their cultural sensitivity. It is crucial to understand that the apparent obsession is actually a calculated move to retain the largest audience or readers, a task increasingly harder in a highly segmented market.

However, the cascade of Wiki leaks exposes have revealed Bill and Hillary Clinton as exports in legalized corruption. Their personal wealth, after leaving the White House, has increased by terms of Millions of dollars. The couple also controls a billion dollar charity, the Clinton Foundation. Paid for by corporate America and foreign Governments.

On the other side, Donald Trump has openly bragged about buying of politicians, saying he was compelled to act with in the frame work of an already corrupt system. In the decades that the Media made trump famous, they failed to bring out facts that have come to light in the course of campaign. Media presented Trump as a successful businessman, with serious political side. This image building by the Media continued many months in to the Trump campaign. Only recent investigations have revealed his cool business judgment, flouting of the law, bribing election officials, gaming the American taxation system and his sham charities.

\subsection{The Importance of the Media}

The media are essential to democracy, and a democratic election is impossible without of media. A free and fair election is not only about the freedom to vote and the knowledge of how cast a vote, but also about a participation process where voters engage in public debate and have adequate information about parties, policies, candidates and the election process itself in order to make informed choices. Furthermore, media acts as crucial watchdog to democratic elections, safeguarding the transparency of the process. Indeed, a democratic election with no media freedom or stifled media freedom would be a contradiction in terms. The numerous ways in which media ensure democratic electoral process 
generally fall into one of the following categories, i.e. 1) media as transparency / watchdog, 2) media as a campaign platform, 3) media as an open forum for debate and discussion / public voice 4) media as public educator.

Print media displace the greatest diversity of all, in both ownership and content. Print media ranges from daily to weekly newspapers, from news magazines to a range of special interest publication. Print media in a sense has more longevity, as it is exists for longer periods of time.

Media shows two characteristics that it comes to coverage of politics and elections. First, the news media have a tendency to focus on the "horse race 'and the campaign process. Who is ahead and who is behind. Second, the impact of media coverage on the public in terms of the issues they care about, their preferences, and so on is limited (Miller, 1991)

\subsection{The Importance Photo Coverage}

Photographs, however, play a vital role in the formation impressions of candidates. A number of studies have found that manipulations in various photo characteristics including facial expression and camera angle can produce changes in evaluation candidates. Over the course of campaign, voters will be exposed to hundreds of photographs of each candidate in various media. A systematic difference in the presentation of the candidates would be evidence of a strong advantage given to one candidate to over the other.

\subsection{Research on Photo Coverage}

Analysis of photographs forms its own sub aria of researches under this category. Often the researcher is interested in how a political actor or event is usually depicted in the media and categorization scheme is used as on exploratory device. Content of photographs is different from the analysis of words because of the amount of time a researcher invests in this research. One reason for its tediousness is that photographers can't be analyzed using computer techniques like words can. Each photograph must be analyzed manually, so to speak. Although researchers have been working on computerized methods for analyzing pictures. For example Robert Timemens at university of Utah. Others do not see it coming to fruition for quite some time for example of David Fan at the University of Minnesota. Despite its laborious nature, many researchers find picture analysis an important aria to study.

\section{LITERATURE REVIEW}

The assessment of political Communication through content analysis has been an approach to methodological research in the communications field for nearly a century (Baran\&Davis, 2009). Though conceptualized and promoted by thought leaders like Harold Lasswell and Paul Lazorsfeld in the early $20^{\text {th }}$ Century (Baran \& Davis , 2009), the advancement of the science over several decades did not progress " in relation to other types of methodological approaches" (Janowitz, 1968). Moriarty and Popovich coded photos published in national news weekly magazines during the 1988 presidential election. Their coding scheme included nine measures of candidate representation and two measures of photo itself. Significant differences were found in a number of measures, most notably expression, were Bush was shown more positively

Khan (2013) did a Quantitative content analysis of photos and the captions carried on the websites of The New York Times and The Economist to understand the visual framing of Iran's 2009controversial presidential election. Khan Collected 102 Photos from the three Newspapers Websites and put them into different framing categories. The study found that the three newspapers websites gave considerably more visual coverage to the runner- up candidates Mousavi, than the incumbent reelected president, Ahmadinedjad. This implies that Mousavi gained more prominence overall coverage than Ahmadinedjad.

\section{RESEARCH OBJECTIVES}

The purpose of the study was to analyzed the photo coverage the 2016 American Presidential Coverage by the India Newspapers in terms of the fallowing specific objectives

1. To find out photo coverage to U.S. Presidential candidates in the selected Indian dailies.

2. To understand the different variables of photo coverage in selected dailies. 
3. To find out the direction of treatment of photo coverage's by selected newspapers.

4. To study the trend analysis in photo coverage.

\section{SELECTION OF NeWSPAPERS}

The Times of India and The Hindu were purposively chosen because it was considered among the top most newspapers in terms of circulation and readership.

\section{SAMPLE}

In order to assess the pictorial environment of the 2016 Presidential Campaign, the researchers under to a content analysis of photographs appearing in the two highest, circulation broadsheets of India. Although the sample is not necessarily a perfect representation of Indian Newspapers. It does offer a picture of campaign as it was portrayed visually in the elite press. Moreover, Newspapers are good barometer of courage they often daily accounts of the campaign. All photos of Trump or Clinton appearing the news sections of Times of India and The Hindu between September 5, 2016 to November 5, 2016. Were coded of the 124 photos included in the study. 66 (53.2\%) were Trump and $58(46.8 \%)$ were Clinton.

\section{Coding Procedure}

The study employed a simplified version of the coding scheme used by Moriarty and her colleagues. The photos were evaluated on five measures, 'expression', 'activity ', 'interaction ', 'background' and 'camera angle'. Each of these components contributes to the overall impression given a photo and conveys subtle cues about a candidate's strengths, ability and level of support. A smiling candidate appears more successful than a frowning one, while an active candidate appears stronger than a passive one. A cheering crowd gives the impression of popular support. American flags invite the viewer to transfer patriotic effect on the candidate. Eye-level shots simulate intimacy shots from below convey power, while shots from above make the candidate appears small.

Table1. Coding Procedure

\begin{tabular}{|l|l|l|}
\hline Variable & More Favorable & Less favorable \\
\hline Expression & Smiling, looking determined & Frowning, looking sad \\
\hline Activity & Speaking at podium, shaking hands & Sitting, reading \\
\hline Interaction & Cheering crowd, smiling or attentive colleagues & Alone or with inattentive others \\
\hline Background & $\begin{array}{l}\text { American flags, science with candidate name, natural } \\
\text { vistas }\end{array}$ & No identifiable background \\
\hline $\begin{array}{l}\text { Camera } \\
\text { Angle }\end{array}$ & Eye level shots & Shots from above \\
\hline
\end{tabular}

\section{DAta Analysis AND ReSUlts}

Table2. Percentage distribution of photo frequency and space by Presidential candidates

\begin{tabular}{|l|l|l|l|l|}
\hline Candidate Name & fr & $\%$ & sp & $\%$ \\
\hline Donald Trump & 66 & 53.2 & 1037 & 51.5 \\
\hline Hillary Clinton & 58 & 46.8 & 976 & 48.5 \\
\hline $\mathrm{N}=$ & 124 & 100.0 & 2013 & 100.0 \\
\hline
\end{tabular}

Out of 124 photos, 66 photos on Donald Trump and 58 photos on Hillary Clinton came up per analysis in those two Indian Newspapers i.e., The Times of India and The Hindu.

Table3. Percentage distribution of photo frequency and space by Presidential candidates in sample dailies

\begin{tabular}{|l|l|l|l|l|l|l|l|l|}
\hline \multirow{2}{*}{$\begin{array}{l}\text { Candidate } \\
\text { Name }\end{array}$} & \multicolumn{9}{|l|}{ Times of India } & \multicolumn{4}{l|}{ The Hindu } \\
\cline { 2 - 10 } & fr & $\%$ & $\mathrm{sp}$ & $\%$ & fr & $\%$ & $\mathrm{sp}$ & $\%$ \\
\hline Trump & 33 & 56.9 & 475 & 58.6 & 33 & 50.0 & 562 & 46.8 \\
\hline Hillary Clinton & 25 & 43.1 & 336 & 41.4 & 33 & 50.0 & 640 & 53.2 \\
\hline $\mathrm{n}=$ & 58 & 100.0 & 811 & 100.0 & 66 & 100.0 & 1202 & 100.0 \\
\hline
\end{tabular}

Among the two newspapers under study The Times of India published the highest number of photographs 33 (56.9\%) on Trump and 25 (43.1\%) on Clinton. Interestingly The Hindu gave equal priority to American presidential candidates Trump and Clinton. In terms of space The Times of India gave more space (58.6\%.) to Trump than Clinton (41.4\%). But The Hindu Clinton scored more space (53.2\%) than Trump (46.8\%). 
MadhuBabuJangili \& NageswaraRaoNamburu

Table4. Percentage distribution of photo frequency and space by candidates with variables

\begin{tabular}{|c|c|c|c|c|c|c|c|c|}
\hline \multirow{2}{*}{ Variable } & \multicolumn{4}{|c|}{ Trump } & \multicolumn{4}{|c|}{ Hillary Clinton } \\
\hline & $\mathrm{fr}$ & $\%$ & $\mathrm{sp}$ & $\%$ & $\mathrm{fr}$ & $\%$ & $\mathrm{sp}$ & $\%$ \\
\hline Expression & 16 & 24.3 & 149 & 14.4 & 20 & 34.5 & 307 & 31.5 \\
\hline Activity & 7 & 10.6 & 116 & 11.2 & 12 & 20.7 & 210 & 21.5 \\
\hline Interaction & 17 & 25.7 & 306 & 29.5 & 15 & 25.9 & 246 & 25.2 \\
\hline Background & 16 & 24.3 & 332 & 32.0 & 4 & 6.9 & 94 & 9.6 \\
\hline Camera Angle & 10 & 15.1 & 134 & 12.9 & 7 & 12.0 & 119 & 12.2 \\
\hline Total & 66 & 100.0 & 1037 & 100.0 & 58 & 100.0 & 976 & 100.0 \\
\hline
\end{tabular}

Only the 'interaction' measure produced all most all equal the two candidates. Clinton scored highest than Trump on 'expression' and 'activity' measures. Trump scored highest than Clinton on 'background' and 'camera angle' measures.

Table5. Percentage distribution of frequency by candidate with the variables in selected dailies

\begin{tabular}{|l|l|l|l|l|l|l|l|l|}
\hline \multirow{3}{*}{ Variable } & \multicolumn{4}{l}{ Trump } & \multicolumn{4}{l|l|}{ Hillary Clinton } \\
\cline { 2 - 10 } & The Times of India & \multicolumn{2}{l|}{ The Hindu } & \multicolumn{2}{l|}{ The Times of India } & \multicolumn{2}{l|}{ The Hindu } \\
\cline { 2 - 10 } & fr & $\%$ & fr & $\%$ & fr & $\%$ & fr & $\%$ \\
\hline Expression & 8 & 24.2 & 8 & 24.2 & 8 & 32.0 & 12 & 36.4 \\
\hline Activity & 4 & 12.2 & 3 & 9.1 & 4 & 16.0 & 8 & 24.2 \\
\hline Interaction & 8 & 24.2 & 9 & 27.3 & 10 & 40.0 & 5 & 15.2 \\
\hline Background & 8 & 24.2 & 8 & 24.2 & 1 & 4.0 & 3 & 9.0 \\
\hline Camera Angle & 5 & 15.2 & 5 & 15.2 & 2 & 8.0 & 5 & 15.2 \\
\hline Total & 33 & 100.0 & 33 & 100.0 & 25 & 100.0 & 33 & 100.0 \\
\hline
\end{tabular}

Table6. Percentage distribution of space by candidate with the variables in selected dailies

\begin{tabular}{|l|c|c|c|c|c|c|c|c|}
\hline \multirow{3}{*}{ Variable } & \multicolumn{4}{|c|}{ Trump } & \multicolumn{4}{c|}{ Hillary Clinton } \\
\cline { 2 - 9 } & \multicolumn{1}{|c|}{ The Times of India } & \multicolumn{2}{|c|}{ The Hindu } & \multicolumn{2}{c|}{ The Times of India } & \multicolumn{2}{c|}{ The Hindu } \\
\cline { 2 - 9 } & $\mathrm{sp}$ & $\%$ & $\mathrm{sp}$ & $\%$ & $\mathrm{sp}$ & $\%$ & $\mathrm{sp}$ & $\%$ \\
\hline Expression & 39 & 8.2 & 110 & 19.6 & 103 & 30.7 & 204 & 31.9 \\
\hline Activity & 73 & 15.4 & 43 & 7.7 & 44 & 13.1 & 166 & 25.9 \\
\hline Interaction & 141 & 29.7 & 165 & 29.3 & 163 & 48.5 & 83 & 12.9 \\
\hline Background & 169 & 35.6 & 163 & 29.0 & 10 & 2.9 & 84 & 13.1 \\
\hline Camera Angle & 53 & 11.1 & 81 & 14.4 & 16 & 4.8 & 103 & 16.2 \\
\hline \multicolumn{1}{|c|}{ Total } & 475 & 100.0 & 562 & 100.0 & 336 & 100.0 & 640 & 100.0 \\
\hline
\end{tabular}

In terms of space, Trump scored highest than Clinton on 'background' and 'interaction' measures. Clinton scored highest space than Trump on 'expression' and 'activity' measures. Two presidential candidates Trump and Clinton almost equally scored on 'camera angle' measure.

These the two dailies differed in their priorities in terms of space devoted to different variables. Considering allocation of space The Times of India and The Hindu published equal number of photographs about Trump on 'expression', 'background' and 'camera angle' variables. Specific difference on 'activity' and 'interaction' variables in both newspapers. In terms of space The Times of India gives more space than The Hindu on 'background' variable. But The Hindu gives more priority on 'camera angle' and 'expression' variable. 'Interaction' variable equally measured in the two newspapers.

The Hindu published more number of Clinton photographs than The Times of India on 'expression', 'activity', 'background' and 'camera angle' variables. The Times of India gave more priority to on 'interaction' variable. In terms of space allocation of photographs, The Hindu gave more space than The Times of India on 'expression', 'activity', 'and background 'and' camera angle'.

Table7. Percentage distribution of photo frequency and space by candidates with directional analysis

\begin{tabular}{|c|c|c|c|c|c|c|c|c|c|c|c|c|c|c|c|c|}
\hline \multirow{3}{*}{ Newspaper } & \multicolumn{8}{|c|}{ More Favorable } & \multicolumn{8}{|c|}{ Less Favorable } \\
\hline & \multicolumn{4}{|c|}{ Trump } & \multicolumn{4}{|c|}{ Hillary Clinton } & \multicolumn{4}{|c|}{ Trump } & \multicolumn{4}{|c|}{ Hillary Clinton } \\
\hline & $\begin{array}{l}f \\
r\end{array}$ & $\%$ & $\mathrm{sp}$ & $\%$ & fr & $\%$ & $\mathrm{sp}$ & $\%$ & fr & $\%$ & $\mathrm{sp}$ & $\%$ & $\begin{array}{l}\mathrm{f} \\
\mathrm{r}\end{array}$ & $\%$ & $\mathrm{sp}$ & $\%$ \\
\hline $\begin{array}{l}\text { The Times } \\
\text { of India }\end{array}$ & $\begin{array}{l}1 \\
2\end{array}$ & $\begin{array}{l}20 . \\
7\end{array}$ & $\begin{array}{l}21 \\
0\end{array}$ & $\begin{array}{l}25 . \\
9\end{array}$ & $\begin{array}{l}1 \\
7\end{array}$ & $\begin{array}{l}29 . \\
3\end{array}$ & $\begin{array}{l}25 \\
3\end{array}$ & $\begin{array}{l}31 . \\
2\end{array}$ & $\begin{array}{l}2 \\
1\end{array}$ & $\begin{array}{l}36 . \\
2\end{array}$ & $\begin{array}{l}26 \\
5\end{array}$ & $\begin{array}{l}32 . \\
7\end{array}$ & 8 & $\begin{array}{l}13 . \\
8\end{array}$ & $\begin{array}{l}8 \\
3\end{array}$ & $\begin{array}{l}10 . \\
2\end{array}$ \\
\hline The Hindu & $\begin{array}{l}1 \\
6\end{array}$ & $\begin{array}{l}24 . \\
2\end{array}$ & $\begin{array}{l}36 \\
0\end{array}$ & $\begin{array}{l}29 . \\
9\end{array}$ & $\begin{array}{l}2 \\
9\end{array}$ & $\begin{array}{l}43 . \\
9\end{array}$ & $\begin{array}{l}56 \\
2\end{array}$ & $\begin{array}{l}46 . \\
8\end{array}$ & $\begin{array}{l}1 \\
7\end{array}$ & $\begin{array}{l}25 . \\
7\end{array}$ & $\begin{array}{l}20 \\
2\end{array}$ & $\begin{array}{l}16 . \\
8\end{array}$ & 4 & 6.1 & $\begin{array}{l}7 \\
8\end{array}$ & 6.5 \\
\hline
\end{tabular}


Table8. Distribution of photo frequency and space by the candidates with more favorable direction of variables in selected dailies

\begin{tabular}{|l|c|c|c|c|c|c|c|c|}
\hline \multirow{3}{*}{ Variable } & \multicolumn{4}{|c|}{ The Times of India } & \multicolumn{4}{c|}{ The Hindu } \\
\cline { 2 - 10 } & \multicolumn{2}{|c|}{ Trump } & Hillary Clinton & \multicolumn{2}{c|}{ Trump } & \multicolumn{2}{c|}{ Hillary Clinton } \\
\cline { 2 - 10 } & $\mathrm{fr}$ & $\mathrm{sp}$ & $\mathrm{fr}$ & $\mathrm{sp}$ & $\mathrm{fr}$ & $\mathrm{sp}$ & $\mathrm{fr}$ & $\mathrm{sp}$ \\
\hline Expression & - & - & 6 & 85 & 3 & 60 & 11 & 184 \\
\hline Activity & 3 & 49 & 3 & 40 & 2 & 39 & 8 & 166 \\
\hline Interaction & 2 & 33 & 7 & 116 & 2 & 51 & 4 & 69 \\
\hline Background & 3 & 99 & - & - & 6 & 147 & 2 & 54 \\
\hline Camera Angle & 4 & 29 & 1 & 12 & 3 & 63 & 4 & 89 \\
\hline \multicolumn{1}{|c|}{ Total } & 12 & 210 & 17 & 253 & 16 & 360 & 29 & 562 \\
\hline
\end{tabular}

Table9. Distribution of photo frequency and space by the candidates with less favorable direction of variables in selected dailies

\begin{tabular}{|l|l|l|l|l|l|l|l|l|}
\hline \multirow{3}{*}{ Variable } & \multicolumn{9}{l}{ The Times of India } & \multicolumn{2}{l|}{ The Hindu } \\
\cline { 2 - 10 } & Trump & \multicolumn{2}{l|}{ Hillary Clinton } & \multicolumn{2}{l|}{ Trump } & \multicolumn{2}{l|}{ Hillary Clinton } \\
\cline { 2 - 10 } & fr & sp & fr & sp & fr & sp & fr & sp \\
\hline Expression & 8 & 39 & 2 & 18 & 5 & 50 & 1 & 20 \\
\hline Activity & 1 & 24 & 1 & 4 & 1 & 4 & - & - \\
\hline Interaction & 6 & 108 & 3 & 47 & 7 & 114 & 1 & 14 \\
\hline Background & 5 & 70 & 1 & 10 & 2 & 16 & 1 & 30 \\
\hline Camera Angle & 1 & 24 & 1 & 4 & 2 & 18 & 1 & 14 \\
\hline Total & 21 & 265 & 8 & 83 & 17 & 202 & 4 & 78 \\
\hline
\end{tabular}

Chi-square $=18.137$, Degrees of freedom $=3, \mathrm{P}-$ value $=0.0004121$

In the present study, an attempt was made to assess the direction of treatment given to the five variables. For this purpose, a three point scale namely 'more favorable', 'less favorable' and 'neutral' was adopted. But, in this study neutral direction was not coded a single photograph. In this reason, neutral was deleted from the table. Between the two dailies, The Hindu put more emphases to the more favorable courage to Clinton than The Times of India. The two newspapers covered less number of photographs to Donald Trump. In the case of space allocation, The Hindu allocated more space to Hillary Clinton. The sample dailies of The Times of India and The Hindu more number of less favorable photographs to Republican candidate Donald Trump. Two newspapers published photographs with less favorability to Democratic candidate Hillary Clinton. Overall, it appears that The Hindu gave more favorable photo coverage to Hillary Clinton has compared to The Times of India. Both the dailies, The Hindu and The Times of India given more number of less favorable photos to Trump.

Changes over time: in charting the photo scores week by week. The researchers identified a clear pattern with the exception of $6^{\text {th }}$ week in the study period (i.e. October $12-18$ ) the total scores of the two candidates moved up and downs in the two newspapers. The spike in Trump scores during the $6^{\text {th }}$ week (October 12-18) (see Figure 1 and 2).

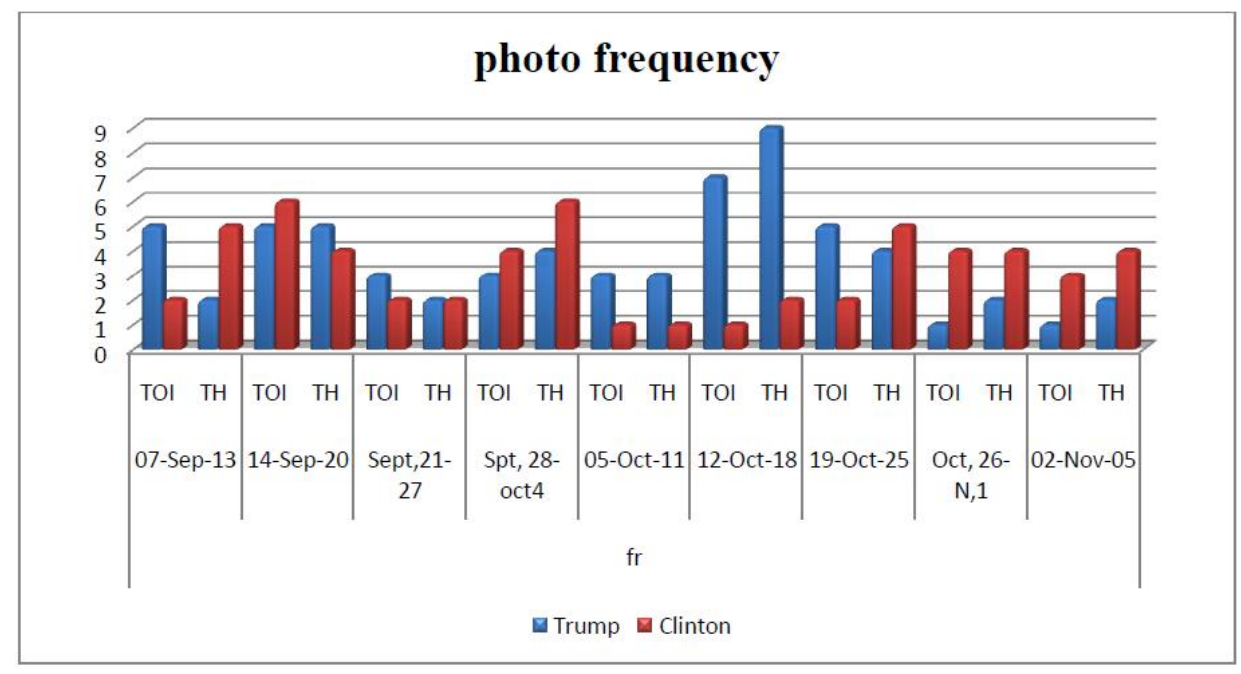

Figure1. Trend line of photo frequency by week and newspaper with Presidential candidates 


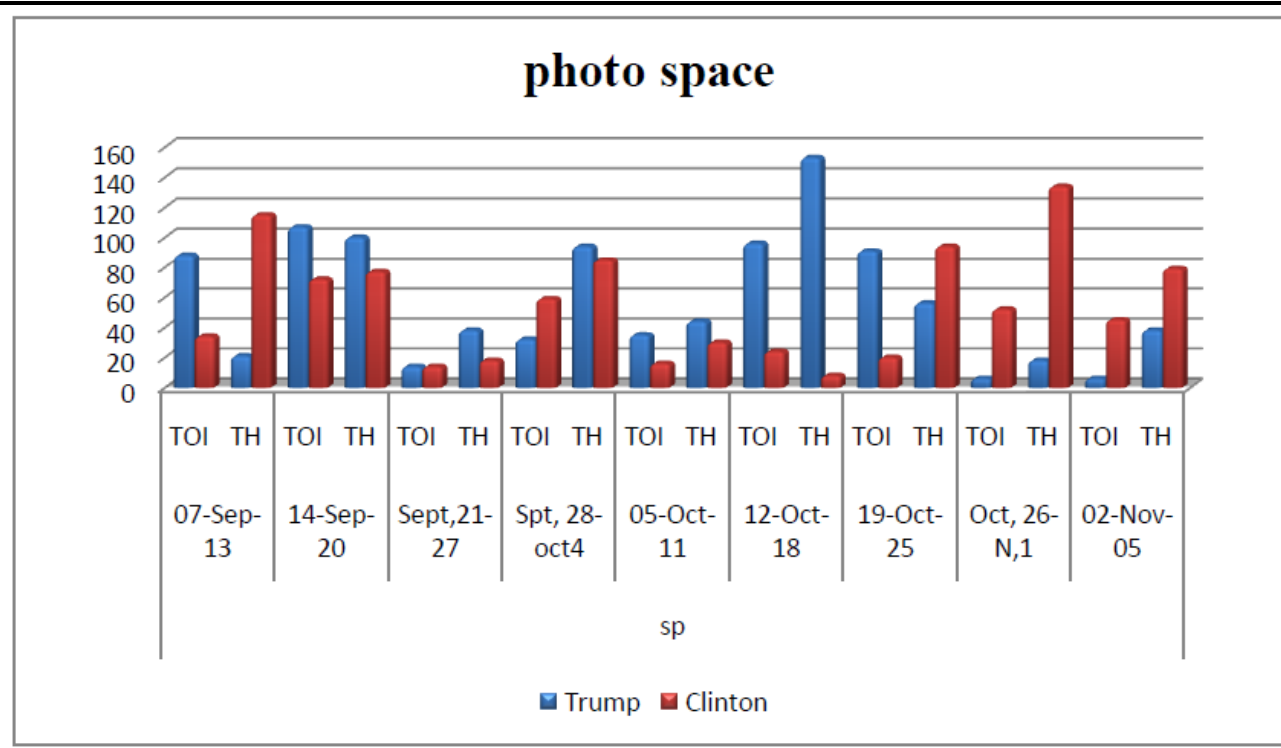

Figure2. Trend line of photo space by week and newspaper with Presidential candidates

\section{CONClusion}

Election campaigning will produce a variety of photographs of a candidate. Some happy and some sad. Newspapers editors must choose which of these shots to use in the next day's edition and which to discard. These choices will have a substantial effect on how the candidate is perceived by the readers. In some cases, how complementary a photograph is to a candidate will be out of the editor's control. Indeed, a well - run campaign will make sure to show the candidate in flattering scenes. At times, the candidates desire to look good and the papers desire from dramatic photos will favor the same shots.

In this content analysis of the newspapers The Times of India and The Hindu shows important difference between their photo coverage of the 2016 American elections. Although, The Hindu newspaper focused on 'expression' variable to the Clinton election campaign. The Times of India gave much interest to highlight the Clintons 'interaction' variable. In the case of Trump photo coverage, The Times of India gave more space to 'background' and follows 'interaction'. But, The Hind, given more space to Trump 'interaction' follows 'background' variables photo coverage.

One must keep in mind that photos meant to illustrate stories. If a story is primarily concern with the candidates relative chances for victory. It would be logical for accompanying photos to advantage the candidate ahead in the polls. Just as she lead in the polls throughout the campaign, Hillary Clinton was portrayed more positively in photographs. It is not help to victory of the Clinton.

\section{REFERENCES}

Baran, S. \& Davis, D. (2009) Mass Communication Theory: Foundations, ferment and future ( $5^{\text {th }}$ ed). Boston: Wads worth Cengage Learning

Janouritz , M. (1968), Harold D , Lasswell's Contribution to content analysis. Public Opinion Quarterly, 32 (4), 646-658.

Khan, B. S. (2013) The Western Media and Iran's Presidential Election 2009: The visual framing of a green revolution. International Journal of Liberal Arts and Social Sciences. Vol.1 No: 4

Miller, William. (1991) Media and Voters: The audience, Content and influence of press and Television at the 1987 General Election. Oxford: Clarendon press.

Moriarty, S.E., \& Garramone, G.M. (1987), A Study of Newspaper Magzine photographs of 1984 Presidential Campaign. Journalism Quarterly, 63, 728-734.

Moriarty, S.E., \& Popovich , P (1991) News Magazine visuals and the 1988 Presidential election. Journalism Quarterly, 68, 371-380. 